\title{
Da leveza como modo de habitar a paisagem: uma experiência
}

Lightness as a way of inhabiting the landscape: an experience

Mariana Libero Hauck Araujo ${ }^{1}$

\footnotetext{
1 Estudante de Artes Plásticas na Escola Guignard/UEMG, desde 2018. Graduada em Turismo pela PUC/MG, com especializações em Gestão Cultural (UNA) e em Desenvolvimento Sustentável Local (UFMG e UNISI/Itália). É bolsista vinculada ao Programa Institucional de Bolsas de Iniciação Científica da UEMG/CNPq, atuando no Projeto de pesquisa próxima paisagem: escola de arte provisória. Em 2019 foi Premiada na XIX Mostra Interna da Escola Guignard, com a série fotográfica "Desvelo", e selecionada para ocupação da Galeria da ALMG, integrante do Coletivo Efêmera. A fotografia se mostra como um modo de investigação plástica. Venho experimentando a presença do meu próprio corpo na paisagem, busco assim evidenciar contrastes e pares de opostos, tais como claro/escuro, peso/ leveza.

Lattes: http://lattes.cnpq.br/4835572159524967
} 


\title{
Resumo
}

O relato de experiência faz parte de um processo de pesquisa em curso no contexto do Projeto de pesquisa/Residência artística próxima paisagem: escola de arte provisória, que acontece no Córrego do Bação, em Itabirito/MG, desde 2018. Na origem dessas fotografias encontra-se uma vivência com a paisagem do Bação, mais especificamente o exercício de percorrer com frequência um determinado caminho, por meio do qual procurei responder à proposição do Projeto próxima paisagem, formalizando assim minha maneira pessoal de perceber, representar e habitar a paisagem do Córrego do Bação, que venho visitando desde outubro de 2018.

\section{Palavras-chave}

Paisagem; fotografia; caminho; perceber e habitar

\begin{abstract}
This experiential account is part of an ongoing research process within the context of a Research Project/Artist Residency Program entitled "próxima paisagem: escola de arte provisória" ("next landscape: provisional art school"), which has taken place since 2018 at Córrego do Bação, located in the municipality of Itabirito, Minas Gerais, Brazil. These photographs stem from an experience with the landscape of Córrego do Bação, namely the act of frequently walking along a certain path. Through this, I sought to answer the proposition laid down by the "próxima paisagem" Project, thus formalizing my personal manner of perceiving, representing and inhabiting the landscape of Córrego do Bação, which I have been visiting since October 2018.
\end{abstract}

\section{Keywords}

Landscape; photography; path; perceiving and inhabiting.

ISSN: 2447-1267 
Revista Apotheke

Percorrer um caminho...

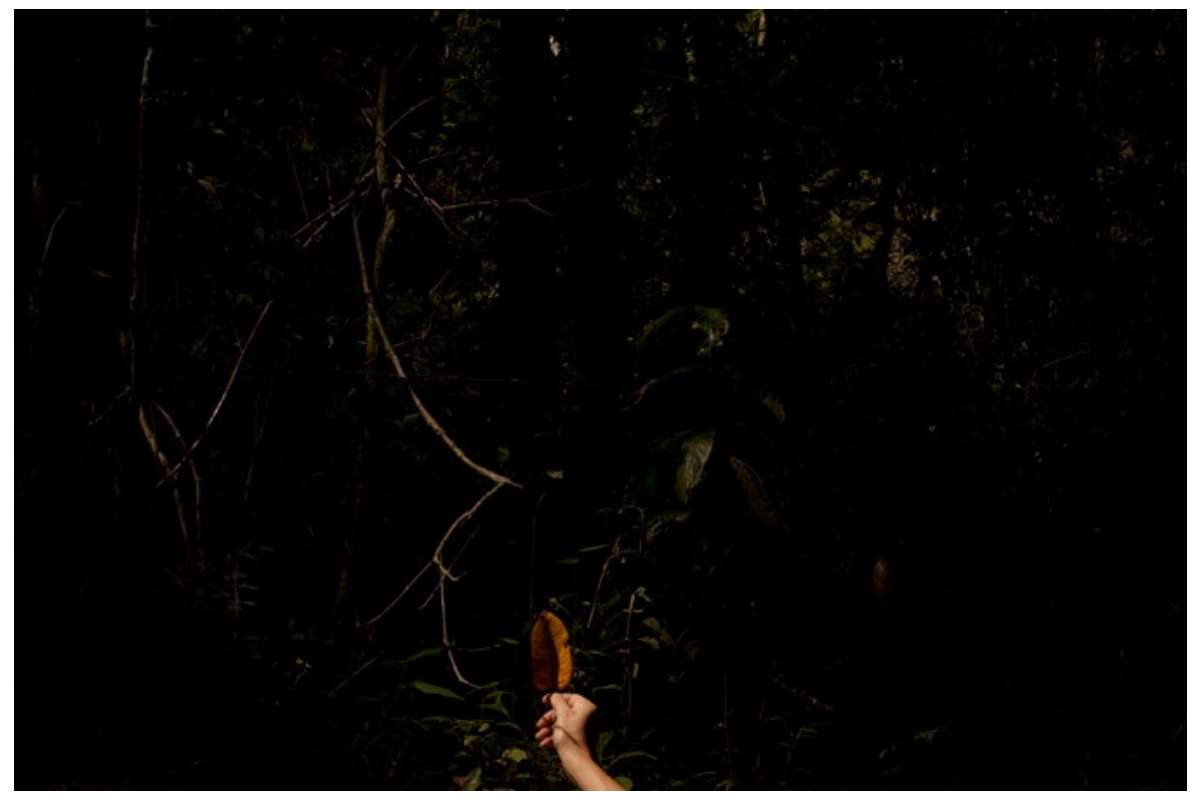

Fig. 1

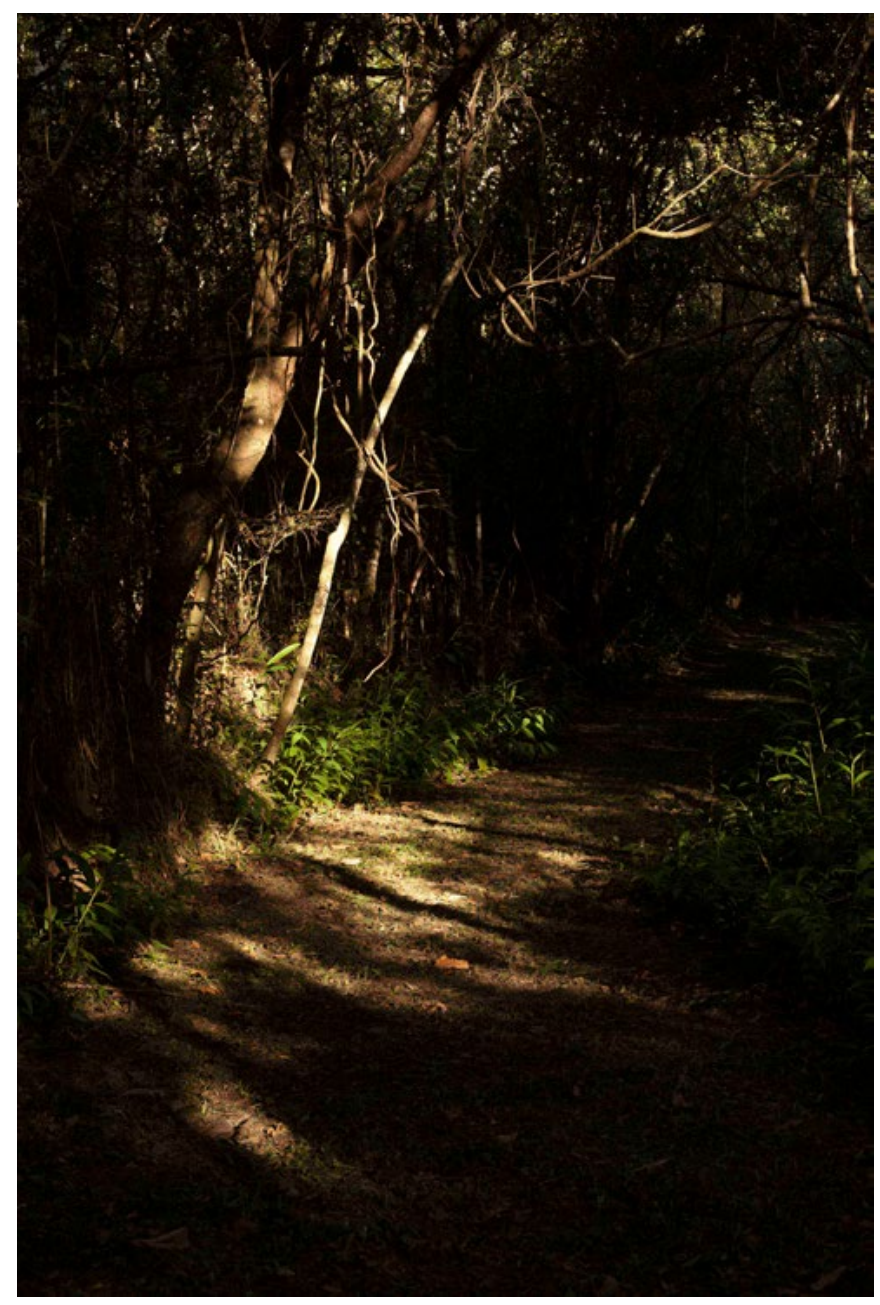

Fig. 2 


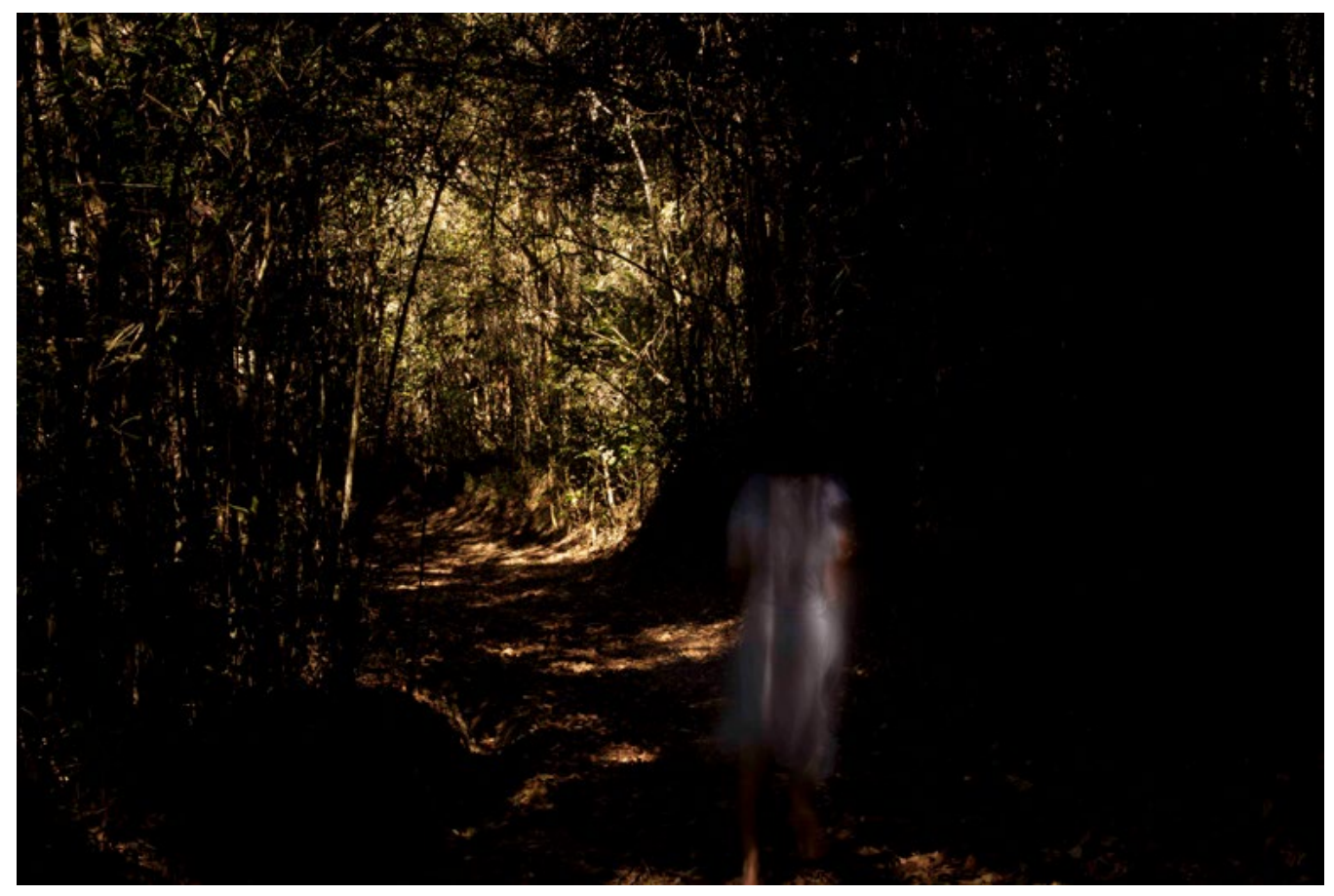

Fig. 3

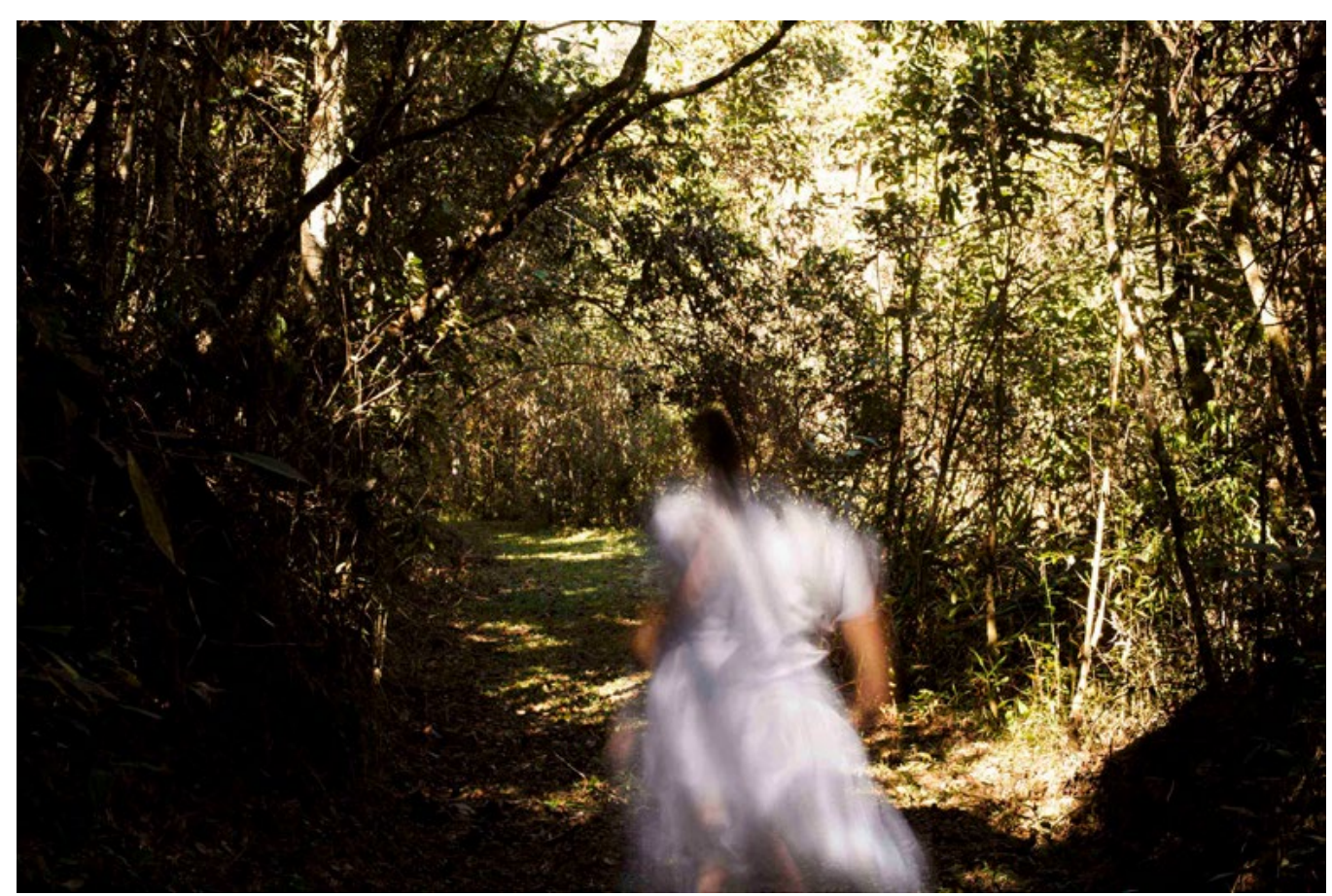

Fig. 4 


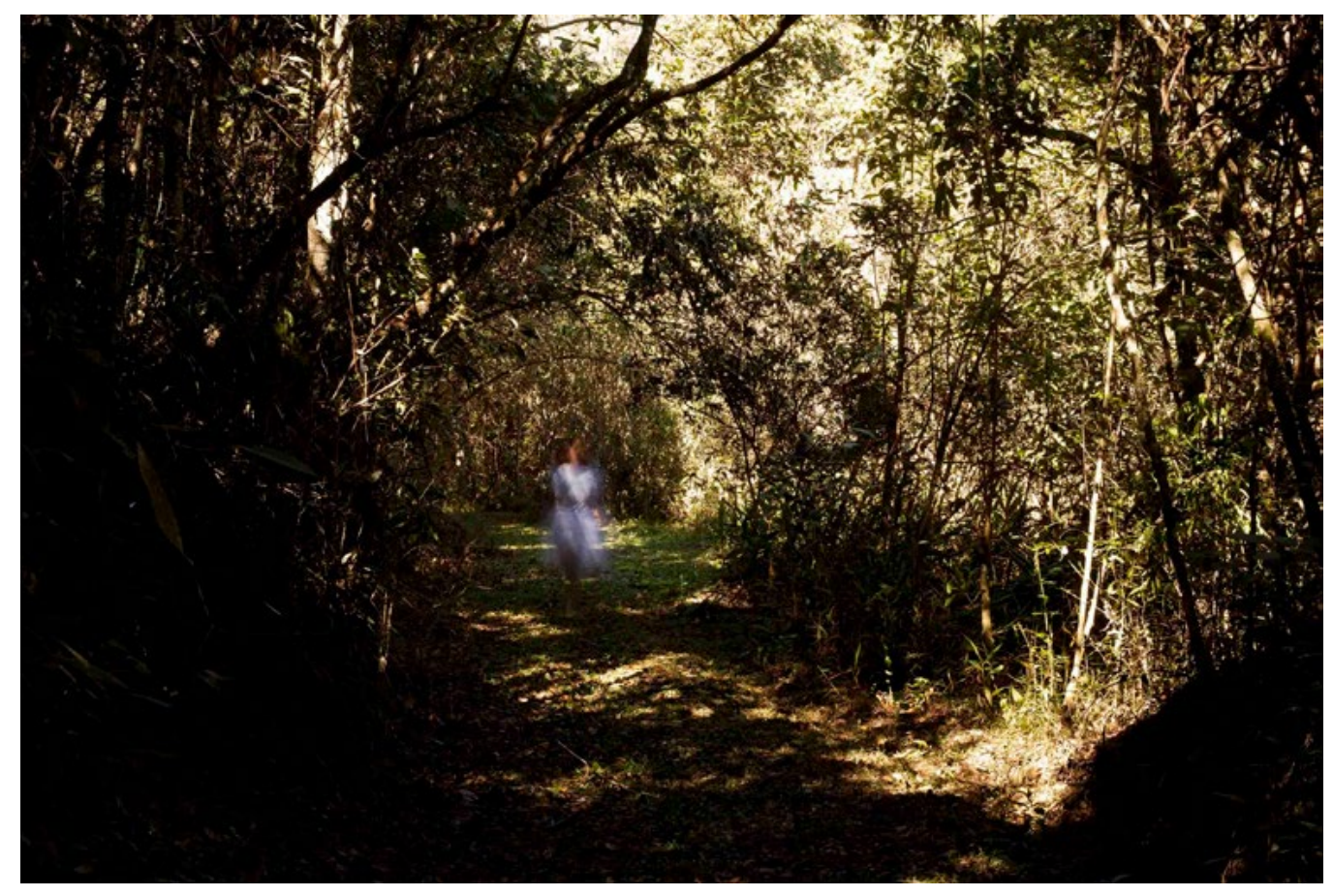

Fig. 5

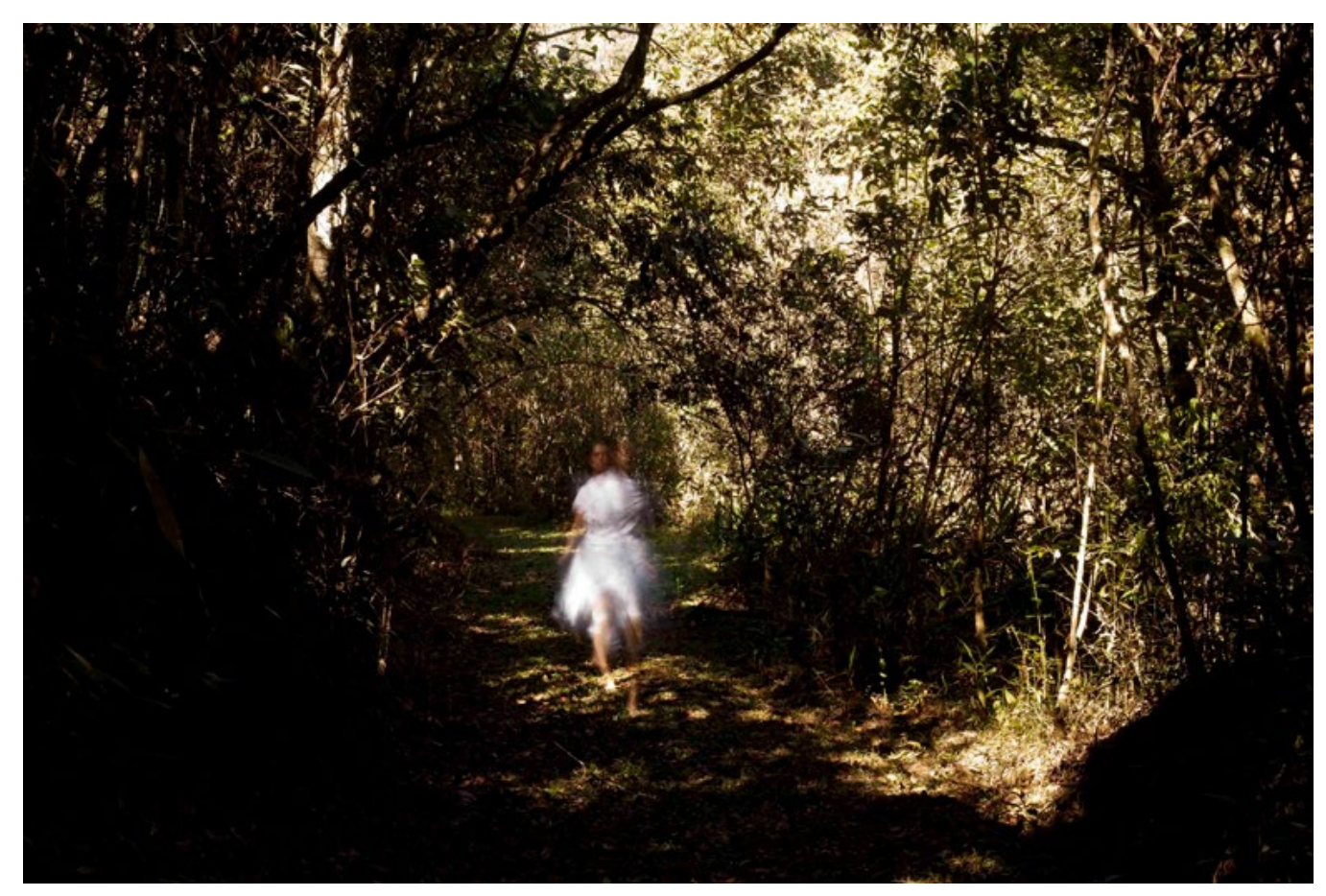

Fig. 6 
Percorri o caminho que leva da Casa Mineira Ateliê até a Prainha no interior da Fazenda Sipuá. Fiz esse caminho na primeira reunião extraordinária do Projeto próxima paisagem: escola de arte provisória ${ }^{1}$. Esse projeto propõe que cinco artistas experimentem maneiras de perceber, representar e habitar a paisagem do Córrego do Bação, em Itabirito, Minas Gerais, por meio de visitas periódicas à região. Envolvida por memórias de infância, por meio das quais me lembro de uma trilha que eu frequentava quando ainda criança, e da imagem de uma pintura na casa dos meus pais, escolhi percorrer esse caminho no interior da fazenda, por percebê-lo íntimo e recluso. A atmosfera que o permeia é bem similar às memórias que tenho da pintura e da antiga trilha de infância. A pintura traz a imagem de um caminho escuro, com alguns feixes de luz que tocam o solo. Assim também me lembro de ser a trilha da infância, com feixes de luz que atravessavam a mata de natureza compacta e chegavam até o chão. $O$ caminho na Fazenda Sipuá é penetrado pela luz, com tons quentes e fortes, mas a densidade da floresta me dá a impressão de estar próxima a um lugar frio e úmido, por causa da sombra causada pela mata fechada. Do mesmo modo, como minhas lembranças de infância, esse novo caminho me acolhe e me remete a uma sensação de pertencimento. No livro "A Poética do Espaço", Gaston Bachelard (2005) escreve sobre a existência do ser humano. Elege a casa como símbolo da experiência de habitar e a relaciona com o sentido de intimidade e com a vivência do espaço. Ele diz que o que constitui a intimidade é a nossa presença no mundo - o nosso modo de ser - e prossegue afirmando que não alcançamos a intimidade antes de habitarmos um lugar. A experiência de "estar em casa" descreve o sentimento de intimidade, e foi essa a sensação que obtive ao permanecer nesse caminho: a de estar em casa e de ao caminho pertencer. Ativada por memórias de infância me identifiquei com esse espaço, e ao percorrê-lo tantas vezes, busquei com ele criar intimidade, com cada curva e com cada canto desse caminho. Enquanto escrevo relembro a experiência. Posso sentir o cheiro das plantas, o perfume acentuado de lírio do brejo. Me recordo das texturas das árvores, algumas mais lisas e outras mais rugosas. Os feixes de luz que tocam a terra molhada e úmida são os protagonistas do trajeto. Como se fossem lanternas, iluminam pontos da trilha, passando pelas brechas das copas das árvores e, com sutileza, tocam elementos que se acendem no espaço: um montinho de folhas secas, uma poça d'água feita depois da chuva, os musgos e liquens presos nas cascas das árvores, infinitos galhos e folhas de tonalidades diversas. Às vezes a luz forma corredores iluminados. Passo por eles e sou tocada pelos feixes, que formam desenhos sobre o meu corpo. Os ruídos do caminho também me chamam a atenção; são sons da natureza que sofrem pausas de silêncio e se modificam ao longo da trilha. No início do caminho ouço o ranger dos troncos dos bambus, logo depois escuto um barulho de folhas e das matas se mexendo com o soprar do vento, escuto os sons dos pássaros. Caminhando para o final da trilha, há um brejo, de onde se inicia um som muito sutil de água correndo; o som aumenta ao longo do percurso até virar um barulho de rio. Movida por esse lugar que se tornou afetivo, peguei a

1 O Projeto próxima paisagem: escola de arte provisória está sendo desenvolvido no contexto do Programa Institucional de Bolsas de Iniciação Científica da UEMG/CNPq, com vigência de agosto de 2019 a julho de 2020, com orientação da professora doutora Fabíola Tasca. 
câmera e o tripé e saí em busca do construção da experiência por meio imagem. Parada frente ao caminho comecei a buscar a luz. No livro "A câmara clara" (2012), Roland Barthes faz reflexões sobre a fotografia e sua relação com o objeto artístico. Salienta que a luz é uma espécie de vínculo umbilical que liga seu olhar à coisa fotografada. O meu olhar dirigia-se para a luz, mas também para as presenças que ela poderia tornar visíveis a partir da inserção do meu corpo na imagem. Desse modo, tive vontade de entrar debaixo da luz e me iluminar com os pequenos feixes. Através do visor da câmera fotográfica vejo um ponto aceso no espaço. Insiro minha mão segurando uma folha que encontro logo ali e uma composição é formada (Fig.1). Os feixes que iluminam os musgos e líquens presos nas cascas das árvores se acendem ainda mais através do enquadramento da câmera. Com um olhar atento congelo o instante que se transforma numa imagem que me recorda a pintura da casa de meus pais e a trilha que percorria na minha infância (Fig.2). A luz é o principal elemento da linguagem visual que compõe a construção pictórica das imagens. Ela pode ser percebida a partir dos contrates de claro e escuro. As atenções e o silêncio voltam-se para a coisa iluminada - a mão que segura a folha e os musgos e líquens presos nas cascas das árvores. Esses elementos tornam-se mais expressivos pela falta de graduação da intensidade dos claros e escuros, "falta" que é antes uma deliberação compositiva. A luz causa uma vibração no espaço, dando a sensação de avanço das partes iluminadas e recuo das partes escuras, as quais criam um ritmo pulsante, e essa pulsação se aprofunda à medida em que se aproxima da tonalidade mais clara - da luz intensa, estabelecendo, assim, o "clímax da composição". Com a técnica fotográfica de baixa velocidade, me fiz desintegrar diante dos feixes de luz (Fig.3). Com borrões, às vezes contornados, outras vezes não completamente, percorri todo o caminho experimentando meu corpo em movimento e a sua interação com o ambiente natural (Figs. 4, 5 e 6). A transparência luminosa dos rastros do meu corpo, em oposição à densidade sombria do ambiente, torna-se um importante elemento pictórico nas imagens (Figs. 3 a 6). Esses vestígios exprimem as sensações de leveza e suspensão experimentadas por mim. Um corpo que estava em busca da luz para obter essa leveza, porém sem se esquecer do peso das sensações, provocadas pela mata densa e escura. Tive um olhar atento para os pontos que evidenciavam o contraste entre claros e escuros, criando uma atmosfera para o caminho e trazendo qualidades pictóricas para a construção da imagem. Milan Kundera (1985), em "A insustentável leveza do ser", cita Parmênides dizendo que a leveza não pode ser separada do peso, assim como luz e sombra são dualidades que não existem isoladas. Portanto a presença dessas dualidades somadas aos rastros do meu corpo constitui um propósito: causar impacto e enfatizar o que mais me interessava naquela experiência - a leveza como forma de habitar. André Brasil (2013) no texto, "Mas o que significa observar?", sublinha que o observador está inserido no meio que observa. Ao nos portarmos como observadores da paisagem, ao buscarmos constituí-la enquanto objeto

\footnotetext{
2 Fayga Ostrower, em seu livro "Universos da Arte", elenca cinco elementos visuais que podem ser considerados no estudo da composição de uma imagem: linha, superfície, volume, luz e cor. Em Desvelo, o elemento luz é utilizado como base da explanação pictórica das imagens, uma vez que é o principal recurso para a composição das imagens resultantes da experiência. Cf. OSTROWER, 1991, pp. 96, 223 a 233.
} 
observado, podemos dizer que, de certa forma, a inventamos, já que a paisagem depende sempre da subjetividade daquele que a observa. E a paisagem, por sua vez, age em nós, transformando-nos em observadores participantes que estabelecem para si normas e condutas de interação. E assim eu me portava, me sentia muito íntima do caminho, como se dele fizesse parte, como se a ele pertencesse. Deixei que a paisagem agisse em mim e criei regras e condutas para com ela interagir, inventando-a. Bachelard diz que a intimidade é também estabelecida na solidão e que é aquecida ao receber o calor do mundo, a amorosidade. A partir daí são constituídos dois mundos, o "próprio mundo" e o "mundo objeto". O devanear, surge quando criamos o nosso próprio mundo. As lembranças e memórias, relativas a lugares nos quais já vivemos, são revividas como devaneios. Desta maneira, o devaneio tem a possibilidade de nos transportar novamente para essas moradas ou casas já vividas. Com essa experiência de percorrer repetidas vezes o trajeto da Casa Mineira Ateliê à Prainha constituí uma espécie de mundo próprio permeado por minhas memórias de infância, a pintura da casa de meus pais e a antiga trilha. Revisitei esses lugares no meu imaginário, e diante desses devaneios solitários inventei uma paisagem que trago aqui por meio da fotografia. "Desvelo" foi o nome que dei à série fotográfica gerada a partir dessa experiência. Desvelo significa remover o véu, agir com zelo, delicadeza

e cuidado. Barthes menciona que fotografia em latim se diz: "imago lucis opera expressa" que significa imagem revelada. Dessa maneira, diante do meu olhar sobre o caminho, busquei revelar o que percebia sobre aquela paisagem, mas também busquei perceber o que a imagem me revelava. Com delicadeza e cuidado, criei intimidade com o espaço, eu o habitei. Experimentei e vivenciei memórias ao sair em busca da luz, à procura da leveza como atitude.

\section{Referências:}

BACHELARD, Gaston. A poética do Espaço. São Paulo. Marins Fontes, 2005.

BRASIL, André. Mas o que significa observar? In: COIMBRA, Eduardo. Museu: observatório. Belo Horizonte. Museu de Arte da Pampulha, 2013.

BARTHES, Roland. A câmara clara. Rio de Janeiro. Nova Fronteira, 2012

KUNDERA, Milan. A insustentável leveza do ser. Rio de Janeiro. Nova Fronteira, 1985.

OSTROWER, Fayga. Universos da Arte. Rio de Janeiro. Campus, 1991.

Recebido em 29 de maio de 2020.

Aprovado em 30 de junho de 2020. 